\title{
The effect of buildings on atmospheric turbulence in open spaces in Western São Paulo State, Brazil
}

\author{
Antonio Jaschke Machado \\ Department of Geography, Faculty of Sciences and Technology, São Paulo State University \\ (UNESP), Presidente Prudente, SP, Brazil \\ E-mail: jaschke.machado@gmail.com
}

\begin{abstract}
This paper seeks to identify a pattern of air turbulence that reflects the effect of buildings on air turbulence characteristics measured in open spaces in Western São Paulo State, Brazil. Atmospheric turbulence was estimated using high-frequency observations of the three orthogonal wind components $(u, v, w)$. A CSAT3 sonic anemometer from Campbell Scientific Inc. (CSI) was deployed on the roof of a building, and the turbulent components ( $\left.u, v^{\prime}, w^{\prime}\right)$ were systematically measured and recorded at $0.1 \mathrm{~s}$ and 5 min intervals, respectively, over 100 days between the end of summer (March 2015) and beginning of winter (July 2015) with a CR3000 automatic data acquisition system (CSI). The data analysis took into account the diurnal and nocturnal variability of the turbulence, and the experimental results revealed the existence of a daily vertical circulation pattern. The w component varied between 15 and $45 \mathrm{~cm} . \mathrm{s}-1$ on average, and the turbulent fluctuations observed indicated that an ascending component with a speed of up to $1 \mathrm{~m} . \mathrm{s}-1$ predominated during the middle of the day and early afternoon. Throughout the night until the early hours of the morning, a less robust, subsiding component with a speed of up to $0.5 \mathrm{m.s}-1$ was observed. The mean horizontal flow $(u, v)$ was low-speed (around $1 \mathrm{m.s}-1$ ) and predominantly from the southeast. There was a consistent change in the direction of this wind, which changed to easterly during the morning as the ascending branch developed. We propose a model for air circulation close to the surface in which this change in direction of the wind is the main effect of the building on the observed turbulence.
\end{abstract}

Keywords: Built environment, sonic anemometer, atmospheric turbulence, open spaces

\section{Introduction}

Turbulence is not completely random; it is almost random (STULL, 1988). When fastresponse sensors are deployed in an open space on top of a building, the signals corresponding to eddies blown by the wind appear to be random. However, when these signals are examined carefully over a long period, a statistically robust signal can be observed. This study seeks to determine the robust component of turbulence and separate it from random fluctuations under the hypothesis that the nature of turbulent fluctuations in open spaces can only be analyzed if we know beforehand the non-random component of the turbulence, which is influenced by the building the sensors are mounted on.

Convective turbulent fluxes of sensible heat and latent heat were quantified for the first time in studies of energy balance on a natural surface using the vapor pressure and temperature gradients observed by Bowen in 1926. In subsequent decades urban surfaces have evolved considerably, and natural surfaces have been replaced by cities that store increasing amounts of anthropogenic and natural energy 


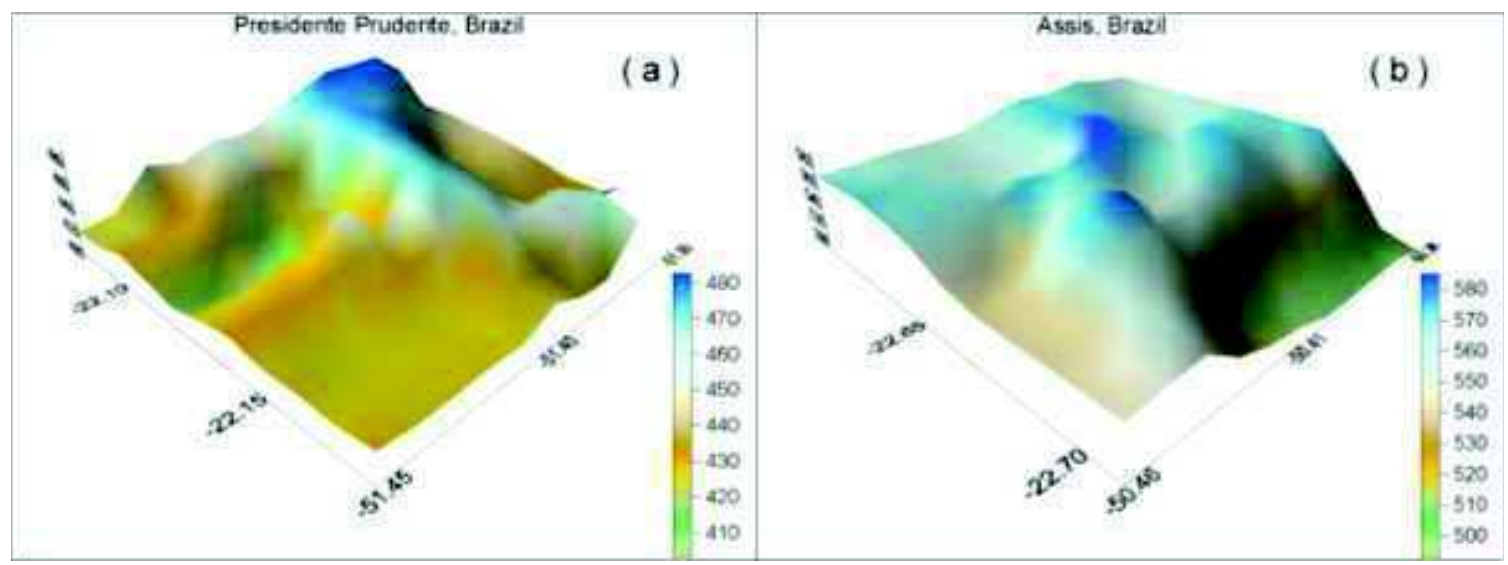

Figure 1.

Geographic location and sampled topography in meters above sea level for urban Presidente Prudente (a) and urban Assis (b) in Western São Paulo State.

and modify the surface ventilation and energy balance (Ribeiro and Azevedo, 2003).

Major efforts have been made since 2006 to analyze in detail the spatial and temporal distribution of radiative and turbulent fluxes inside the urban canopy layer in the state of São Paulo, initially in densely urbanized areas in the east of the state (Machado and Azevedo, 2007; 2013) and from 2012 in the west of the state (Barboza and Machado, 2015), where urbanization is in its early stages.

In light of this, it was decided to carry out a controlled field study to investigate atmospheric turbulence patterns close to the surface. It is reasonable to suppose that, in addition to being influenced by the vehicle fleet and large numbers of pedestrians (Azevedo, 2004), turbulence is influenced by the position of buildings in relation to the sun and wind and their exposure to these. This would support the validity of observations and estimates of turbulent flows acquired on built structures close to the ground and in the middle of open spaces.

\section{Eddy correlation method}

Because of the turbulent nature of air, all atmospheric entities show short-term fluctuations around a longer-term mean fluctuation. Eddies move continuously around surfaces, from which they derive their properties. Hence, an entity ( $\mathrm{s}$ ) can be said to consist of its mean value ( ) and a fluctuating component ( s') (Oke 1987, p.376) so that:

$$
S=\bar{S}+S^{\prime}(1)
$$

where the bar indicates a mean time-averaged property and the dash the instantaneous deviation from the mean. Figure 3a shows very clearly how fluctuations in the vertical component of the wind (w) and temperature (T), for example, combine to produce the instantaneous sensible heat flux $(\mathrm{QH})$. The intensity of the instantaneous flux is calculated from the mean of the product of the intensities of the fluctuations, a technique known as eddy correlation.

The diurnal and nocturnal evolution of the three wind components ( $\mathrm{u}, \mathrm{v}, \mathrm{w})$ and their turbulent fluctuations (u', v', w') can be analyzed in detail with the aid of a Campbell Scientific Inc. (CSI) CSAT3 sonic anemometer using the relationship described in Equation 1.

Observation of the vertical component of turbulent fluctuations (w') is particularly useful for estimating turbulent convective fluxes of both sensible heat $(\mathrm{QH})$ and latent heat $(\mathrm{QE})$, the main fluxes responsible for dissipation of energy stored in a built volume $(\Delta \mathrm{QS})$. The variability of $\Delta \mathrm{QS}$ is proportional to the difference between the energy sources and sinks and can be defined in terms of a balance:

$\Delta \mathrm{Q}_{\mathrm{S}}=\left(\mathrm{Q}^{*}+\mathrm{Q}_{\mathrm{F}}\right)-\left(\mathrm{Q}_{\mathrm{H}}+\mathrm{Q}_{\mathrm{E}}+\Delta \mathrm{Q}_{\mathrm{A}}\right)(2)$ where $Q^{*}$ is the density of the net radiation at all wavelengths observed directly with a Kipp \& Zonen (KZ) NR-LITE-2 net radiometer, $\Delta$ QA represents the heat advected by the horizontal components of the winds $(\mathrm{u}, \mathrm{v})$ and $\mathrm{QF}$ 


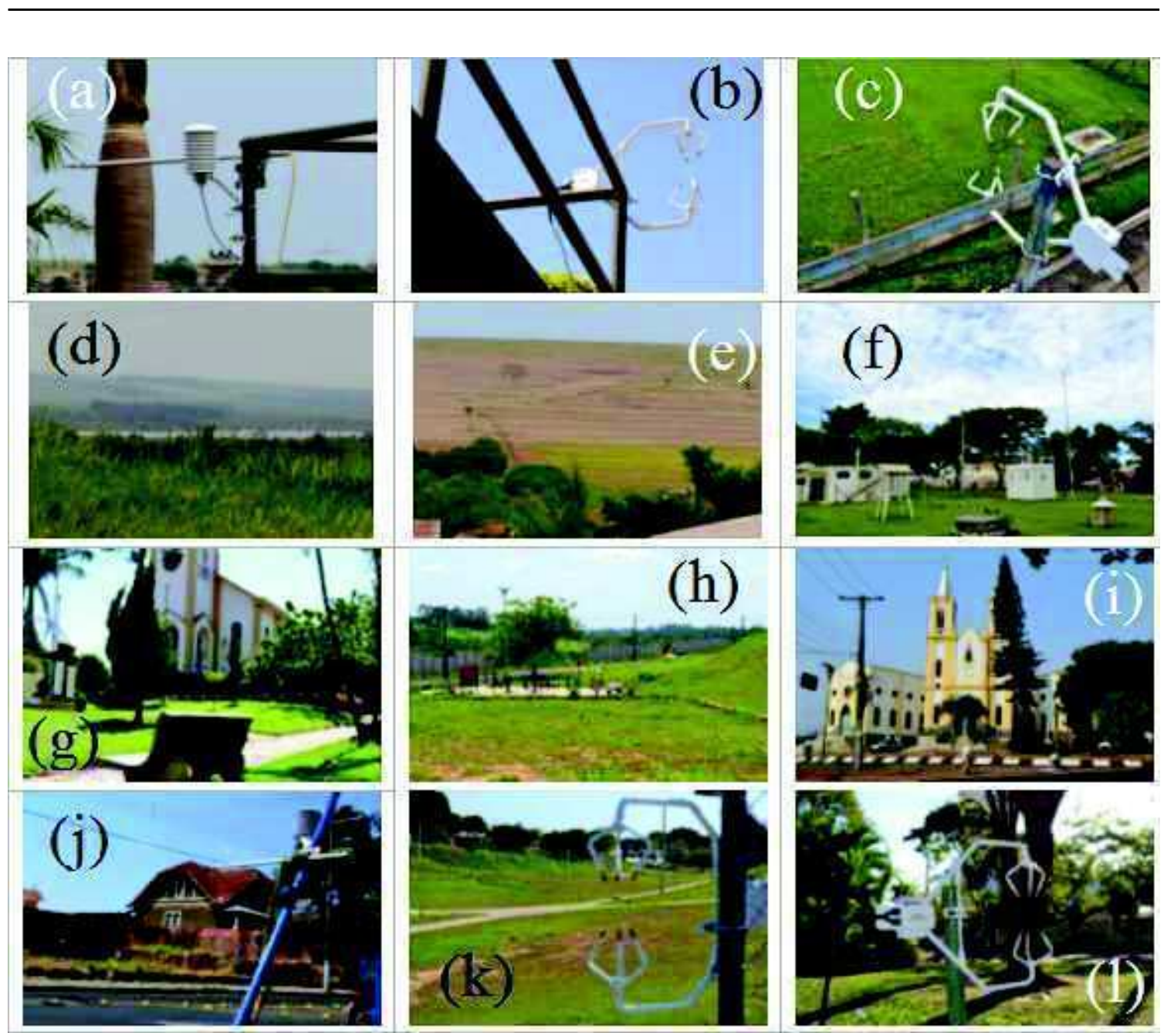

Figure 2.

Net radiometer, pyrgeometer, thermo-hygrometer (a) and sonic anemometer (b, c) deployed on Padre Francisco Penskoffer Square in Iepê (g), near a dam (d), near a plowed field (e) and at the FCT/UNESP meteorological station (f). Open spaces in Presidente Prudente (h, i, k, l) and historical heritage in Assis (j) (modified after Machado, 2016)

represents the heat produced by human activity. An inventory of QF for specific activities has been compiled for Western São Paulo State (Finati and Machado, 2015); the values of QF in this inventory are one order of magnitude smaller than the values for $Q^{*}$. It should be stressed that all the terms in the surface energy balance are heavily influenced by the different types of atmospheric weather that predominate in the area (Pradella, 2014). For this reason, to highlight the effect of the surface on the temporal variability of turbulence, a sample of 100 days of observations was taken starting at the beginning of the dry season, when clear skies tend to predominate.

\section{A brief characterization of the locations where turbulent fluctuations were monitored}

Western São Paulo State is the westernmost region of the state of São Paulo and is located at the meeting point of the Paranapanema River and Paraná River valleys. The largest city in the study area is Presidente Prudente (2207'47’S, $51^{\circ} 24^{\prime} 31^{\prime \prime} \mathrm{W}$ ), which is approximately $600 \mathrm{~km}$ from the Atlantic Ocean and $400 \mathrm{~m}$ above sea level. The municipality extends over some 562 $\mathrm{km} 2$, most of which is rural, and the majority of the 200,000 inhabitants (IBGE 2012) live in a densely populated urban area of around 30 $\mathrm{km} 2$.

Campaigns were carried out in Presidente Prudente and then in the towns of Iepê and 
Assis, to the southeast of Presidente Prudente. Figures $1 \mathrm{a}$ and $1 \mathrm{~b}$ show the main features of the landform in the region of urban Presidente Prudente and Assis, respectively, in the extreme northwest and southeast of the study area. Topographic sampling and georeferencing during the 2012 campaign showed that the mean altitude in Presidente Prudente is approximately $100 \mathrm{~m}$ less than in Assis. The landform in the Iepê urban area is significantly simpler than in Presidente Prudente and Assis and is therefore not shown. It consists essentially of a steep west-facing slope close to the bottom of the Paranapanema River valley and some $500 \mathrm{~m}$ above sea level. The Assis urban area is located on the edge of an intermediate terrace, while Presidente Prudente is located on a broad ridge.

The landscape in towns and cities in Western São Paulo State is characterized by a great variety of urban forms, a typical feature of contemporary Brazilian landscape (Macedo, 2012). In recent years the contrast between open spaces, such as squares, pedestrian precincts and central areas, and, on the other hand, private spaces, such as housing developments, gated communities and private gardens, has increased markedly. The urban form contrasts strikingly with the surrounding rural area.

\section{Field experiments in open spaces in Western São Paulo State}

Two campaigns were carried out to collect data, the first in 2012 and the second in 2015. In the former, fixed campaigns were carried out in various locations in Presidente Prudente, Assis and Iepê, while in 2015 a fixed experiment was carried out in one location in Presidente Prudente. The present study deals primarily with the analysis of the data collected in the 2015 campaign. The same strategy was used in both the 2012 and 2015 campaigns: deployment of a CSAT3 sensor (CS), net radiometer (KZ), pyrgeometer (KZ) and thermo hygrometer (Vaisälla) on existing urban structures at heights of between 1 and 3 $\mathrm{m}$ above the ground (Figs. 2a, 2b).

Time series data for the wind components, net radiation, longwave radiative flux, air temperature and air humidity were recorded at these locations over intervals ranging from a few hours to a complete diurnal cycle from sunrise to sunset. The wind data, which were the subject of analysis in this study, were acquired automatically with a CR3000 (CSI) data acquisition system at a frequency of $10 \mathrm{~Hz}$ and stored at $1 \mathrm{~s}$ intervals. All the observation sites were georeferenced, and their elevations above sea level were sampled with an automatic GPS (Garmin).

In March 2015 the CSAT3 was deployed on the Presidente Prudente Meteorological Station building (Figs. 2c, 2f) in a controlled experiment and has remained in operation there since then. Wind components are recorded continually during the day and night. The sampling frequency of $10 \mathrm{~Hz}$ used in the 2012 campaign was maintained, but the recording interval was increased to $5 \mathrm{~min}$.

During the 2012 campaign, measurements were made on urban fixtures in public squares and roads (Figs. 2i, 2j) and occasionally near rural areas (Figs. 2d, 2e). Unlike in other cities, the green areas in open spaces in Presidente Prudente (Figs. 2h, 2k) are used much more as places to walk through rather than as places to linger in. As a general rule, there are few trees (Fig. 21). The design of these green spaces tends to be based on a recurring geometric formalism (Figs. 2g, 2i), and even the shapes and coverings of the church façades vary little. A very limited number of buildings retain their cultural and historical value (Fig. 2j), illustrating the poorly or inadequately restored architectural heritage passed down from the Europeans who colonized the area in the first half of the 20th century.

\section{Measurement and analysis}

\section{Explosive convective events observed using eddy correlation}

A large eddy was observed in Iepê amid small eddies (Fig. 3). Apparently it was a large eddy that had started on the surface of the dam or in the very large ploughed field close to the city. The surface energy balance, which depends on the removal of heat by the convective flux QH (Fig. 3a), suggests an intra-urban breeze 


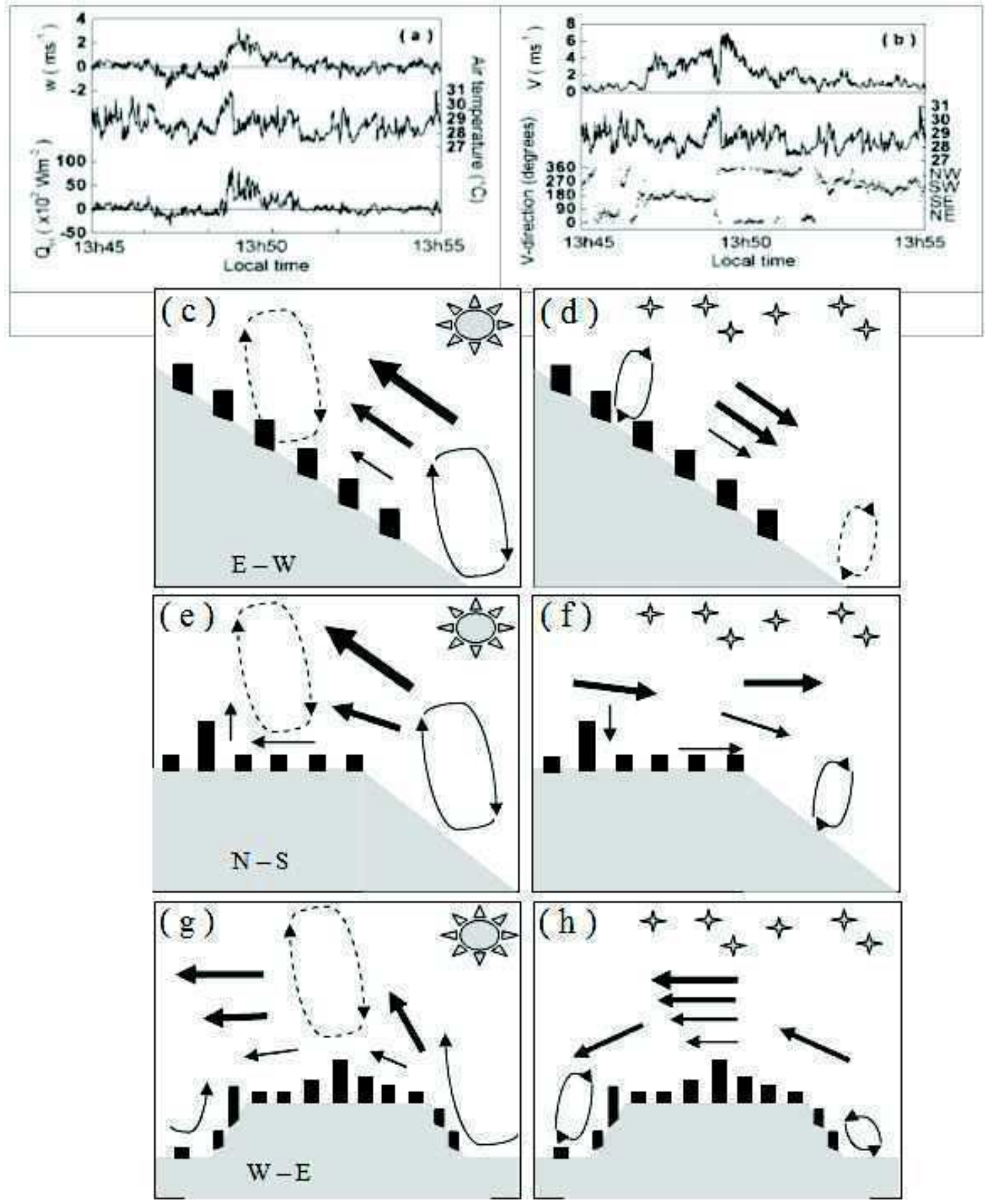

Figure 3.

Comparison of a large eddy amid small eddies represented by the flux QH (a) and observed breeze (b). The other diagrams are schematic representations at times $t$ (solid line) and $t+1$ (dotted line) of large eddies in the boundary layer circulation during the day (c, e, g) and night (d, f, h) in Iepê (c, d), Assis (e, f) and Presidente Prudente (g, h). The light gray areas represent the topographic profiles for each of the urban areas studied, and the black rectangles represent the buildings. The direction of the circulation is shown for a meridional direction (N-S) and a zonal direction (E-W or W-E) (modified after Machado, 2016).

possibly caused by a convective explosive event (Fig. 3b). The breeze is characterized by a sudden change in direction between 13:45 and 13:50, when it is consistently southerly, while before and after that it is predominantly northerly.

The sensible heat flux transported by this large eddy reaches the impressive figure of 


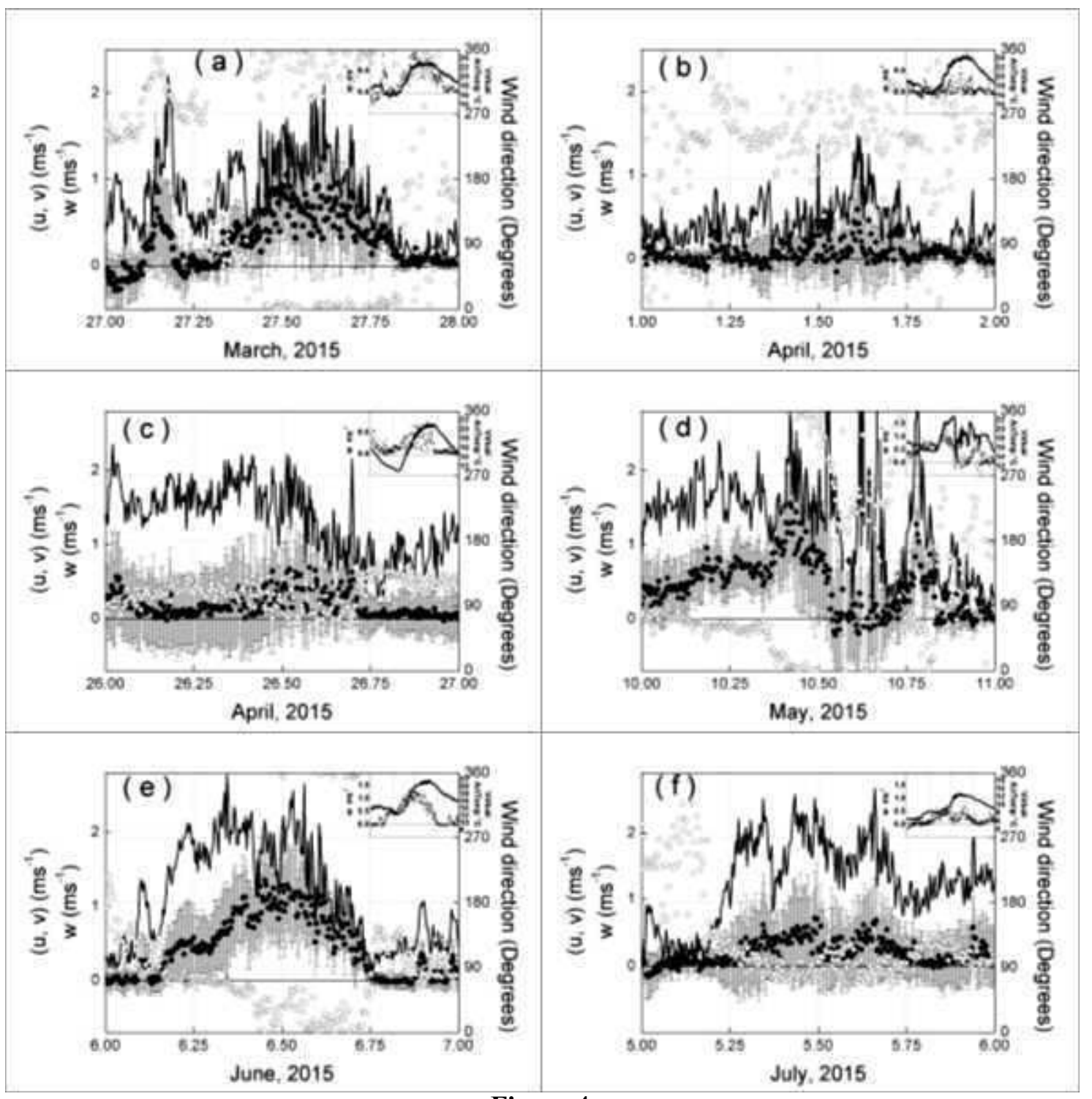

Figure 4.

Vertical wind component (black circles), horizontal wind component (continuous line) and wind direction (white circles) on March 27th (a), April 1st (b), April 26th (c), May 10th (d), June 6th (e) and July 5th (f) 2015. The error bars represent the standard deviation of the vertical component. The graph in the top-right corner shows the vertical component (circles) and virtual temperature (continuous line)

$8000 \mathrm{Wm}-2$ during this $5 \mathrm{~min}$ period, 400 times the mean flux QF generated by human activities in a metropolis extending over 2,500 km2 (Azevedo, 2001).

In an attempt to illustrate the dynamics of these large eddies, various schematic representations of the circulation at the boundary layer associated with the basic characteristics of the topography and land cover are proposed (Figs. 3c-h). This relationship between, on the one hand, circulation and, on the other, landform and urban morphology may be the reason for the diurnal and nocturnal turbulence patterns observed.

The measurements taken in Western São Paulo State indicate that the wind blows mainly from the east. Depending on the orientation and location of the urban settlement, this flow leads to different turbulence configurations during the day and night. Each of the urban areas studied here had very different locations and orientations: the town of Iepê is located close to 


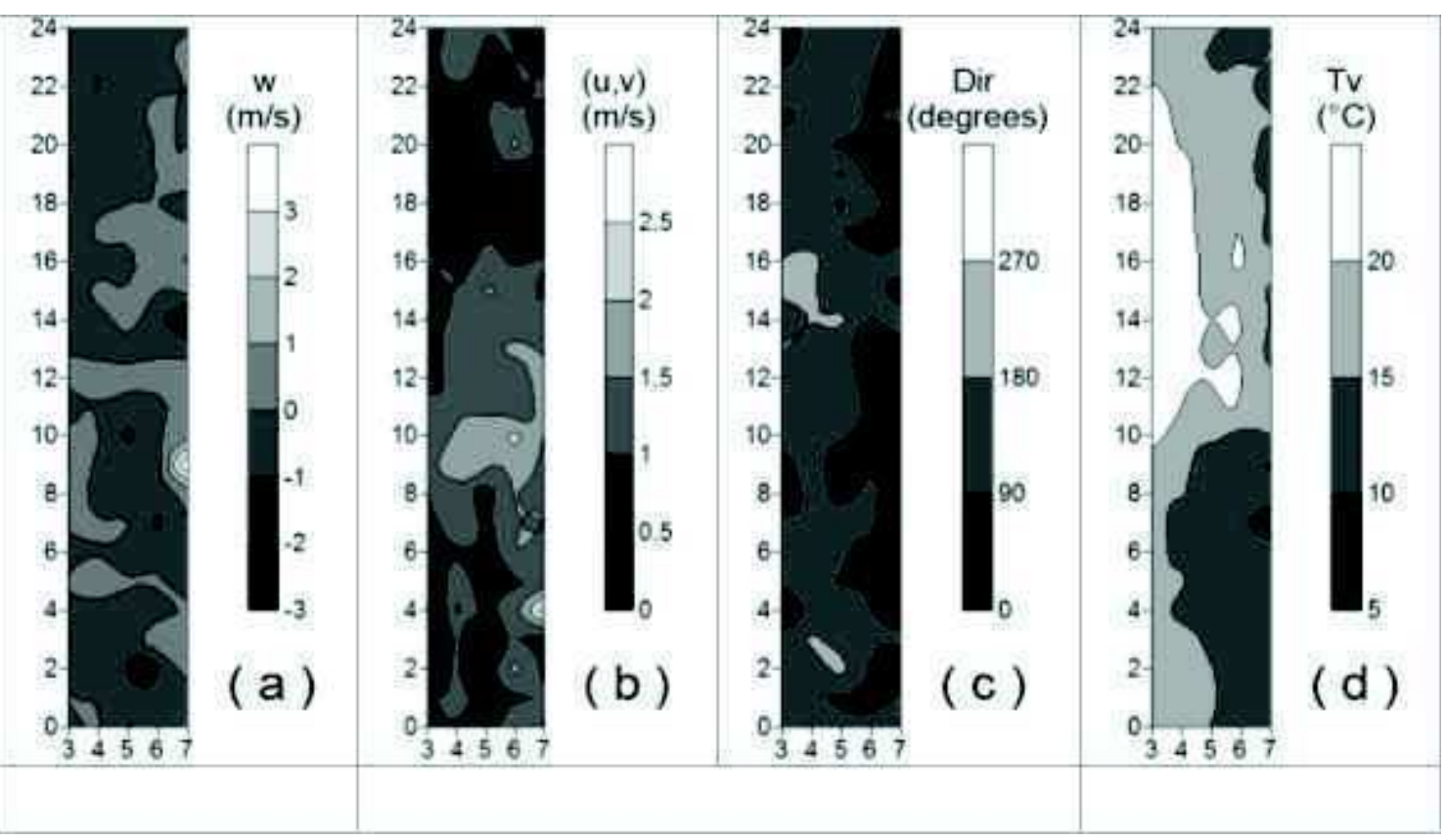

Figure 5.

Vertical wind component (a), horizontal wind component (b), wind direction (c) and virtual temperature (d) as a function of time (vertical axis) and month of the year (horizontal axis, starting in March). Sonic anemometer deployed at the UNESP meteorological station / Presidente Prudente (2015)

the bottom of the Paranapanema valley, Assis is higher up on a large terrace and Presidente Prudente extends along a broad ridge on the lowlands leading to the Paraná valley. The Iepê urban area is situated on west-facing slope, and the town of Assis lies in an east-west direction bordered on the south by the edge of the terrace leading to the Parapanema River, while Presidente Prudente lies mainly in a northsouth direction on the top of the hills that make up the broad ridge lying in the same direction.

In the schematic representations based on observations at the surface, the large eddies circulate at right angles to the prevailing wind

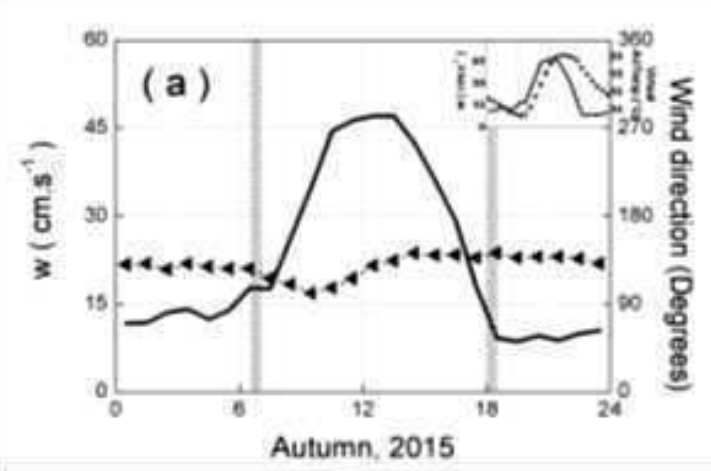

in Assis, while in Iepê and Presidente Prudente the large eddies formed on the steep slopes oppose or follow the prevailing circulation and are accordingly favored or inhibited by it.

In the case of Assis, the town's location on a plateau at the top of a slope helps to divert the eddies above the urban canopy. A more intense version of the same effect can be observed in Presidente Prudente, where the range of elevations is $50 \mathrm{~m}$ greater than in Assis (Figs. 1a and $1 \mathrm{~b}$ ) and there are more tall buildings, both factors that lead to a deeper turbulent boundary layer.

\section{Figure 6.}

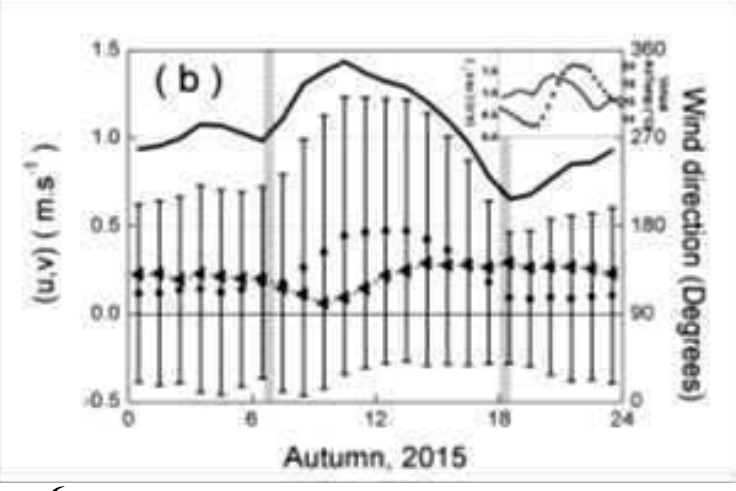

Vertical wind component (a), horizontal wind component (b), wind direction (c) and virtual temperature (d) as a function of time (vertical axis) and month of the year (horizontal axis, starting in March). Sonic anemometer deployed at the UNESP meteorological station / Presidente Prudente (2015) 


\section{Diurnal and nocturnal evolution of} turbulence inside the urban canopy layer

Atmospheric turbulence in the urban canopy layer is highly complex. Continuous observation of the variability of the vertical wind component (w) and its fluctuations (w') as well as the variability of the horizontal wind component $(\mathrm{u}, \mathrm{v})$ shows that there are diurnal and nocturnal patterns (Fig. 4). Fluctuations of the horizontal component (u', v'), which were also measured but are not shown here, were negligible compared with w' and will be discussed in a future study. Initially w is analyzed in relation to the horizontal component, wind direction and virtual temperature (Fig. 4a). Then the observed variability of the vertical component itself is included in the analysis (Fig. 4b-f). The intensity of the turbulence is directly proportional to this variability, and it can be seen that the turbulence increases as the wind speed increases. This mechanical effect is also accompanied by a thermal effect. As diurnal heating increases during the morning, an increase in the intensity of the turbulence can also be observed even though relatively weak winds with speeds below $2 \mathrm{~m}$.s-1 predominate.

Figure 5 shows the evolution of the vertical component, horizontal component, wind direction and virtual temperature during the day and night for different months of the year. Initially the horizontal component tends to be weaker from the beginning of the night until just after dawn (Fig. 5b). This pattern only changes with the onset of winter, when wind speeds in excess of 2 m.s-1 are observed at around 4:00 AM. Moderate winds during the early hours of the morning may be related to a nocturnal low-level jet, a meteorological phenomenon associated with nocturnal stratification of the lower atmosphere that is more pronounced during the cold months.

The vertical component is also stronger at the end of the fall and beginning of winter (Fig. 5a), with a well-defined ascending branch in the early morning and a descending branch in the early afternoon. The direction of the horizontal component is shown in Figure 5c. Easterly winds predominate, with winds tending to be southeasterly at the beginning of the fall and turning to northeasterly at the end of the fall.
Southwesterly winds may be associated with the passage of intense frontal systems.

To clarify whether circulation was subject to thermal effects, the virtual temperature (TV) estimated by the CSAT3 is shown in Figure 5d. The pattern identified is similar to that typically associated with a clear sky, i.e., maximum temperatures during the afternoon and cooling during the early hours of the morning. This result was to be expected, given that there tend to be more days with this type of sky in Western São Paulo State.

\section{Expected variability}

The results in Figure 6 were obtained with the CSAT3 (Fig. 2c) installed on the northern façade of the one-story flat-roofed building at the UNESP meteorological station (Fig. 2f) and are the mean values of data collected over a 100-day period at the end of fall and beginning of winter 2015.

The presence of a building in the landscape produces aerodynamic changes in the surrounding environment, with the ascending wind component accelerating in the morning and decelerating in the afternoon (Fig. 6a).

The airflow pattern over the edge of the building, one of the façades of which is at a right angle to the incident wind, is shown in Figure 6 b. After sunrise the wind speed increases until it reaches almost $1.5 \mathrm{~m} . \mathrm{s}-1$ and the direction of the wind changes from southeast to east. During the afternoon the speed decreases to close to $0.5 \mathrm{~m} . \mathrm{s}-1$ and the wind changes back to southeasterly.

The vertical wind component reaches a maximum before TV does, suggesting that the ascending current is driven by radiative surface heating and implying a transfer of energy from the surface to the urban canopy layer. TV follows a smooth cycle with a daily temperature variation of approximately $7^{\circ} \mathrm{C}$, indicating that although the 100 days monitored were not specifically chosen, the result is similar to that expected for a clear sky. This finding is not unexpected as clear skies or skies with few clouds predominate at this time of year. Although $w$ is one order of magnitude smaller than $(\mathrm{u}, \mathrm{v})$, its temporal fluctuations are 

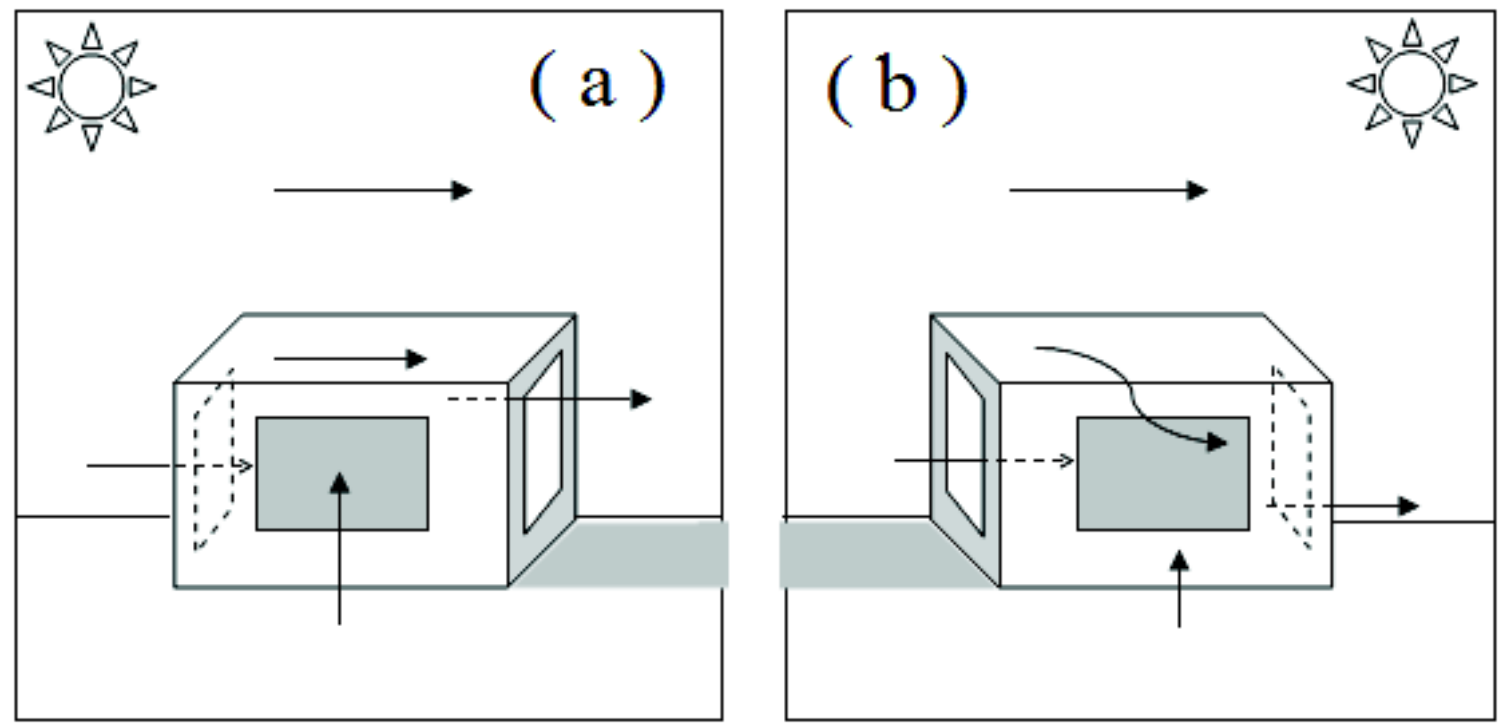

Figure 7.

Schematic representation (based on the results of this study) of the air flow around and through a building whose major axis lies in an E-W direction during the morning (a) and afternoon (b) (modified after Machado, 2016)

of the same order of magnitude as those for ( $\mathrm{u}$, v). This indicates that not only heat but also momentum is transferred by the flow w. It is not by chance that $(\mathrm{u}, \mathrm{v})$ increases toward a maximum at the same time as the ascending morning current develops, increasing the complexity of any analysis of the presence of the building in the landscape.

\section{The effect of the building on the surrounding airflow}

Based on the results presented above, a model can be drawn up to illustrate how the airflow around a building in the urban canopy changes during the day (Fig. 7). At sunrise (Fig. 7a), an ascending current parallel to the northern façade gains strength. This current directs the flow over the top of the building, and the flow remains easterly until the end of the morning. After midday the air is diverted from the top of the building as the sun disappears over the horizon (Fig. 7b), and this situation continues throughout the night until dawn the following day. Without the support of the rising current, the air starts to flow down the walls of the building.

This external effect has implications for the internal space. During the morning the air inside the building acquires the characteristics of the outside air close to the ground (which is hotter and made up of particles from the surrounding surface), circulates inside the building and then leaves through the tallest windows. From midday, and throughout the afternoon and night until dawn the following day, the air inside the building acquires the characteristics of the fresher, higher air, which consists of various particles transported from and dispersed by sources making up the urban structure upwind of the building being analyzed.

\section{Conclusion}

The findings of this study can be expected to help identify coherent patterns in the atmospheric turbulence observed close to the surface. By relating an ephemeral timescale of only a few minutes to timescales of the order of hours or even months, eddies of various spatial dimensions can be identified.

Analysis of the seasonal variation in turbulence would appear to be a sensible practice, as it allows a consistent daily pattern to be identified. This pattern proved to be the product of two factors: the spontaneous thermal convection produced by surface heating and cooling during the day and night; and the presence of the building, which generally increased the mechanical turbulence.

The results of this study not only help to understand how the airflows around a building 
develop during the day and night but also allow the eddies in the free spaces investigated to be evaluated with a greater degree of certainty. It is hoped that the findings will prove useful in the design of thermally efficient landscape projects. However, further studies with larger data sets are required to validate the results presented here.

\section{Acknowledgments}

The author would like to thank the State of São Paulo Research Foundation (FAPESP) for providing financial support (ref. no. 2011/08520-8) and the anonymous reviewers whose comments helped to improve this article.

\section{References}

Azevedo, T. R. (2001) 'O fluxo de calor gerado pelas atividades humanas'. In: Tarifa, J. R.; Azevedo, T. R. (orgs.). Os climas da cidade de São Paulo: teoria e prática, Departamento de Geografia, FFLCH, Universidade de São Paulo, São Paulo (in Portuguese).

Azevedo, T. R. (2004) 'A frota de automóveis e o pó que São Paulo respira: particulado inalável no clima da cidade'. Geografias de São Paulo: representação e crise da metrópole. São Paulo: Editora Contexto, 1,73 - 88 (in Portuguese).

Barboza, E. C.; Machado, A. J. (2015) 'Bowen ratio in Western São Paulo State, Brazil'. In: International Conference on Building, Architecture and Urbanism, 17, Barcelona. Proceedings ...: WASET, 17(10), 17701773.

Ferreira, M. J.; Oliveira, A. P. de; Soares, J. (2013) 'Diurnal variation in stored energy flux in São Paulo city, Brazil'. UC Urban Climate, 5(1), 36-51.

Finati, G. I.; Machado, A. J. (2015) 'Diurnal evolution of anthropogenic heat released by kitchens and its relation to the energy balance at the surface in western São Paulo state, Brazil'. PARC Pesquisa em Arquitetura e Construção, 6(2), 103-119 (in Portuguese).

Garrat, J. R. (1992) The atmospheric boundary layer. Cambridge University Press.
Ibge (2015) Instituto Brasileiro de Geografia e Estatística. Disponível em < http://www. censo2014.ibge.gov.br/ > . Acessado em 3 de julho (in Portuguese).

Landsberg, H. E. (2006) 'The climate of towns'. Tradução de Tarik Rezende de Azevedo. In: Revista do Departamento de Geografia, 18, 95-111 (in Portuguese).

Macedo, S. S. (2012) Paisagismo brasileiro na virada do século: 1990-2010. São Paulo e Campinas: EDUSP/ Editora UNICAMP, $344 \mathrm{p}$ (in Portuguese).

Machado, A. J.; Azevedo, T. R. de (2007) 'Detection of the urban heat-island effect from a surface mobile platform'. Revista de Teledetección. Valladolid: Agéncia Española de Teledetección, 27, 59-70.

Machado, A. J.; Azevedo, T. R. de. (2013) 'Spatial distribution in long-wave radiation flux in São Paulo city, Brazil'. WJEPS World Journal of Engineering and Physical Sciences, 1(3), 33-52.

Machado, A. J. (2016) 'Daily evolution and seasonal variation of atmospheric turbulence in open spaces in Western São Paulo State, Brazil'. Labor \& Engenho, 10(4), 330-342 (in Portuguese).

Oke, T. R. (1987) Boundary Layer Climates. 2nd ed. (Routledge, London).

Oke, T. R. (2006) 'Towards better scientific communication in urban climate'. Theor. Appl. Climatol., 84, 179-190.

Pradella, H. L. (2014) A construção do conceito de "tipos de tempo" entre os séculos XVII e XXI, no âmbito das Ciências Atmosféricas. 370 p. Dissertação (Mestrado em Geografia Física) - Faculdade de Filosofia, Letras e Ciências Humanas, Universidade de São Paulo, São Paulo (in Portuguese).

Ribeiro, H.;Azevedo, T.R.(2003) 'O patrimônio em áreas verdes da USP e atmosfera urbana'. In: Comissão de Patrimônio Cultural da USP. Meio Ambiente: Patrimônio Cultural da USP. São Paulo, 19-39 (in Portuguese).

Stewart, I. D.; Oke, T. R. (2012) 'Local climate zones for urban temperature studies'. BAMS Bulletin of American Meteorological Society, 93(12), 1879-1900.

Stull, R. B. (1988) An Introduction to Boundary Layer Meteorology. London, Kluwer Academic Publishers. 
Tarifa, J. R.; Armani, G. (2001) 'Os Climas Urbanos'. In: Tarifa, J. R.; Azevedo, T. R. (org). Os climas da cidade de São Paulo: teoria e prática, Departamento de Geografia, FFLCH, Universidade de São Paulo, São Paulo (in Portuguese). 